\title{
On the One Trigonometric Interpretation-The Decomposition Loophole
}

\author{
Jiří Stávek ${ }^{1}$ \\ ${ }^{1}$ Prague, Czech Republic \\ Correspondence: Jiří Stávek, Prague, Czech Republic. E-mail: stavek.jiri@seznam.cz
}

Received: October 7, 2013 Accepted: November 12, 2013 Online Published: November 26, 2013

doi:10.5539/apr.v5n6p131 URL: http://dx.doi.org/10.5539/apr.v5n6p131

\begin{abstract}
The gist of this contribution is the search for a possible decomposition loophole in relativistic formulae. An attempt is presented where trigonometric mathematical instruments have been used in order to decompose the quantity "c- - the light speed constant" into two components - the first one describing the longitudinal speed of the source and the second one describing the transverse vibrational speed of a quantum particle. The Matzka-Voigt complex number describing mathematically longitudinal speed of the source and transverse vibrational speed of quantum particles was postulated. The modulus of the Matzka-Voigt complex number equals to $|\mathrm{c}|=|\lambda v|=299,792,458 \mathrm{~ms}^{-1}$ and can be inserted into the Maxwell's equations. The known trigonometric functions were used to interpret graphically the "relativistic formulae" and to decompose these formulae into their components. This trigonometric approach opens a new way to interpret the quantitative data in the Euclidean space: "vis activa", "vis viva", "vis mortua", kinetic energy, Doppler effect, quantum of formal action, etc. This trigonometric interpretation of "relativistic formulae" can be tested experimentally in the proposed experiments.
\end{abstract}

Keywords: trigonometric functions, complex speed, modulus and norm of complex numbers, "vis activa", "vis viva", "vis mortua", kinetic energy, quantum of formal action

\section{Introduction}

The relativistic formulae have been tested with the admirable experimental accuracy during the $20^{\text {th }}$ century: e.g., Albert Einstein in 1905, Rindler in 1991, Taylor and Wheeler in 1992, Tipler and Llewellyn in 2002, Feynman, Leighton and Sands in 2005. However, this approach forces us to postulate the spacetime elasticity. The scientific literature is full of many attempts to find an "interpretation loophole" in this concept. There is one permanent dilemma: did we achieve the final possible mathematical description of Nature or are there any possible "hidden loopholes" that wait for their discovery?

The history of the search of "hidden loopholes" in the special relativity formulae is very rich and can be now easily traceable using the Wikipedia. One interesting approach is the expression of relativistic formulae with hyperbolic functions in the 3D space promoted by Whittaker in 1910, Varićak in 1910, Robb in 1911, and recently refreshed by Dray in 2003 and Barett in 2011. There are some other geometrical descriptions of the special relativity formulae: e.g., Carroll in 2004, Crabbe in 2004, Bros in 2005, Delphenich in 2005, Ungar in 2009, Dragon in 2012, and Naber in 2012.

We will use the analogy with the prime factorization which is known to be a very difficult problem and many sophisticated prime factorization algorithms have been devised for special types of numbers. Can we find a trigonometric decomposition algorithm for the decomposition of the relativistic formulae into components that could describe the events in the $3 \mathrm{D}$ space?

In this contribution we propose to use trigonometrical mathematical instruments and to decompose the quantity "c- - the light speed constant" into two components - the first one describing the longitudinal speed of the source and the second one describing the transverse vibrational speed of a quantum particle. The known trigonometric functions will be used to interpret graphically the "relativistic formulae" and to decompose these formulae into their components. The decomposition of the quantity "c - the light speed constant" was nearly achieved by Woldemar Voigt in 1887. We will combine the mathematical instruments of Wilhelm Matzka from 1850 with Woldemar Voigt from 1887 in order to present a possible "decomposition loophole" for the quantity "c- - the 
light speed constant". Three experimental tests will be proposed to verify this "decomposition loophole" and to estimate if this trigonometric concepts brings something new for this field of the research.

\section{Wilhelm Matzka and His Interpretation of Complex Numbers}

There are very well-known contributions of mathematicians to the topic of the geometrical interpretation of complex numbers: Caspar Wessel in 1799, Jean Robert Argand in 1806, Augustin-Louis Cauchy in 1821, and Carl Friedrich Gauss in 1831.

In 1850 Wilhelm Matzka published his book "Versuch einer richtigen Lehre von der Realität der vorgeblich imaginären Grössen der Algebra, oder einer Grundlehre von der Ablenkung algebraischer Grössenbeziehungen". ("An Attempt at a Correct Theory of the Reality of Supposed Imaginary Numbers in Algebra, or a Basic Knowledge of the Deflection of Algebraic Quantitative Relations"). In this book Matzka proposed the original description of complex numbers as agglomerates of the longitudinal and transverse motions and added arrows to those numbers in order to describe their motion in the space.

We can use the Matzka's way of writing of complex numbers as a stimulating aid for the description of photon properties: Euler-Matzka bits. See the page 158 of the Matzka's book "Versuch...".

Table 1. Matzka's writing of complex numbers: Euler-Matzka bits

$\mathrm{z}_{1}=\rightarrow \mathrm{a}+\uparrow \mathrm{b}=|\mathrm{z}|(\rightarrow \cos \theta+\uparrow \sin \theta)=\rightarrow \mathrm{e}^{\uparrow \theta}|\mathrm{z}|$
$\mathrm{z}_{2}=\leftarrow \mathrm{a}+\uparrow \mathrm{b}=|\mathrm{z}|(\leftarrow \cos \theta+\uparrow \sin \theta)=\leftarrow \mathrm{e}^{\uparrow \theta}|\mathrm{z}|$
$\mathrm{z}_{3}=\leftarrow \mathrm{a}+\downarrow \mathrm{b}=|\mathrm{z}|(\leftarrow \cos \theta+\downarrow \sin \theta)=\leftarrow \mathrm{e}^{\downarrow \theta}|\mathrm{z}|$
$\mathrm{z}_{4}=\rightarrow \mathrm{a}+\downarrow \mathrm{b}=|\mathrm{z}|(\rightarrow \cos \theta+\downarrow \sin \theta)=\rightarrow \mathrm{e}^{\downarrow \theta}|\mathrm{z}|$

The details about the life and other mathematical works of Wilhelm Matzka can be found in the excellent biography written by Michaela Chocholová and Ivan Štoll.

3. Matzka-Voigt Complex Number with its Modulus $\left|\mathrm{z}_{\mathrm{MV}}\right|=|\mathrm{c}|=|\lambda \mathrm{v}|=\mathbf{2 9 9 , 7 9 2 , 4 5 8 \mathrm { ms } ^ { - 1 }}$

We will take the inspiration from the Wilhelm Matzka's description of the complex numbers and combine it with mathematical approach of Woldemar Voigt who formulated the Voigt transformation for the transverse photon waves in 1887 (See Ernst and Hsu in 2001).

We will get the Matzka-Voigt complex number as the aggregate of the longitudinal speed of the source and the transverse particle vibrational speed. In this agglomerate $\rightarrow(\mathrm{v})$ is the longitudinal speed of the source and $\downarrow\left[\mathrm{c} V\left(1-\mathrm{v}^{2} / \mathrm{c}^{2}\right)\right]$ is the periodical transverse particle speed:

$$
z_{M V}=\rightarrow(v)-\downarrow\left(c \sqrt{1-\frac{v^{2}}{c^{2}}}\right)
$$

The modulus of this Matzka-Voigt complex number is $\left|\mathrm{z}_{\mathrm{MV}}\right|=|\mathrm{c}|=|\lambda v|$. We propose to use this modulus $|\mathrm{c}|$ in the Maxwell equations. In the Maxwell's equations, the relation between electricity, magnetism, and the modulus of the light speed can be summarized by the equation:

$$
|c|=|\lambda v|=\frac{1}{\sqrt{\mu_{0} \varepsilon_{0}}}=\sqrt{v^{2}+c^{2}\left(1-\frac{v^{2}}{c^{2}}\right)}
$$

where $|\mathrm{c}|$ is the modulus of the light speed, $\lambda$ is the wavelength of the transverse particle vibration, $v$ is the frequency of the transverse particle vibration, $\mu_{0}$ is the permeability of free space, $\varepsilon_{0}$ is the permittivity of free space, the term $\rightarrow(v)$ is the longitudinal speed of the source, and $\downarrow\left[\mathrm{c} \downarrow\left(1-\mathrm{v}^{2} / \mathrm{c}^{2}\right)\right]$ is the transverse vibrational speed of the photon particle.

Now we can modify the Principle of Invariant Light Speed of Albert Einstein from the year 1905: "...light is always propagated in empty space with a definitive velocity $c$ which is independent of the state of motion of the emitting body" as the Principle of Invariant Modulus of the Light Speed: "Light is always propagated in space with a definitive modulus of the light speed $|c|$ which is independent of the state of motion of the emitting body". 
For the case of addition of velocities $\mathrm{v}_{1}+\mathrm{v}_{2}$ we can modify the Matzka-Voigt complex number as:

$$
z_{M V}=\left(\rightarrow\left(v_{1}+v_{2}\right)-\downarrow\left(c \sqrt{1-\frac{\left(v_{1}+v_{2}\right)^{2}}{c^{2}}}\right)\right)
$$

The source keeps its longitudinal speed $\rightarrow \mathrm{v}$, while the photon simultaneously periodically vibrates in the transverse direction with the speed $\downarrow\left[\mathrm{c} \sqrt{ }\left(1-\mathrm{v}^{2} / \mathrm{c}^{2}\right)\right]$ and the period $\downarrow T$ in the transverse direction:

$$
\downarrow T=\downarrow\left(\frac{T_{0}}{\sqrt{1-\frac{v^{2}}{c^{2}}}}\right)
$$

where $\downarrow T_{0}$ represents the period of the vibration in the transverse direction for the longitudinally motionless source of that particle. The instruments that measure time based on the transverse vibrational principle of particles are therefore influenced by the longitudinal motion of those instruments.

\section{Doppler-Matzka Effect}

Christian Doppler derived his famous formula to describe the dependence of the observed wavelength and frequency on the relative motion of the source and the observer in 1842. For the rapidly moving quantum particles we have to insert into this formula the correction for the period $\left(\downarrow T / \downarrow T_{0}\right)$ for the periodical transverse vibration of these particles:

$$
\begin{aligned}
\lambda & =\lambda_{0}\left(1 \pm \frac{\left|v_{1}-v_{2}\right|}{c}\right) \cdot \downarrow\left(\frac{T}{T_{0}}\right)=\lambda_{0}\left(1 \pm \frac{\left|v_{1}-v_{2}\right|}{c}\right) \cdot \downarrow\left(\frac{1}{\sqrt{1-\frac{\left|v_{1}-v_{2}\right|^{2}}{c^{2}}}}\right)= \\
& =\lambda_{0}\left(1 \pm \frac{v_{r e l}}{c}\right) \cdot \downarrow\left(\frac{1}{\sqrt{1-\frac{\nu_{r e l}^{2}}{c^{2}}}}\right) \\
v & =\nu_{0}\left(1 \mp \frac{\left|v_{1}-v_{2}\right|}{c}\right) \cdot \downarrow\left(\frac{T}{T_{0}}\right)=\nu_{0}\left(1 \mp \frac{\left|v_{1}-v_{2}\right|}{c}\right) \cdot \downarrow\left(\frac{1}{\left.\sqrt{1-\frac{\left|v_{1}-v_{2}\right|^{2}}{c^{2}}}\right)=}\right. \\
= & \nu_{0}\left(1 \mp \frac{v_{r e l}}{c}\right) \cdot \downarrow\left(\frac{1}{\sqrt{1-\frac{v_{r e l}^{2}}{c^{2}}}}\right)
\end{aligned}
$$

It is a historically interesting fact that Christian Doppler and Wilhelm Matzka took the same position of the professor of mathematics on the Prague Polytechnic (now Czech Technical University). Doppler took this position in the years 1841-1847 and Matzka in the years 1849-1850 (later Matzka was the professor of mathematics on the Prague University in the years 1850-1871). (For further details see the biography written by Chocholová and Štoll).

\section{Trigonometric Interpretation of Relativistic Formulae}

Figure 1 surveys the known trigonometric functions in the circle with radius $\mathrm{R}=1$ and the defined value $\cos (\theta)=$ $\mathrm{v} / \mathrm{c}(\mathrm{v} / \mathrm{c} \leq 1)$. 


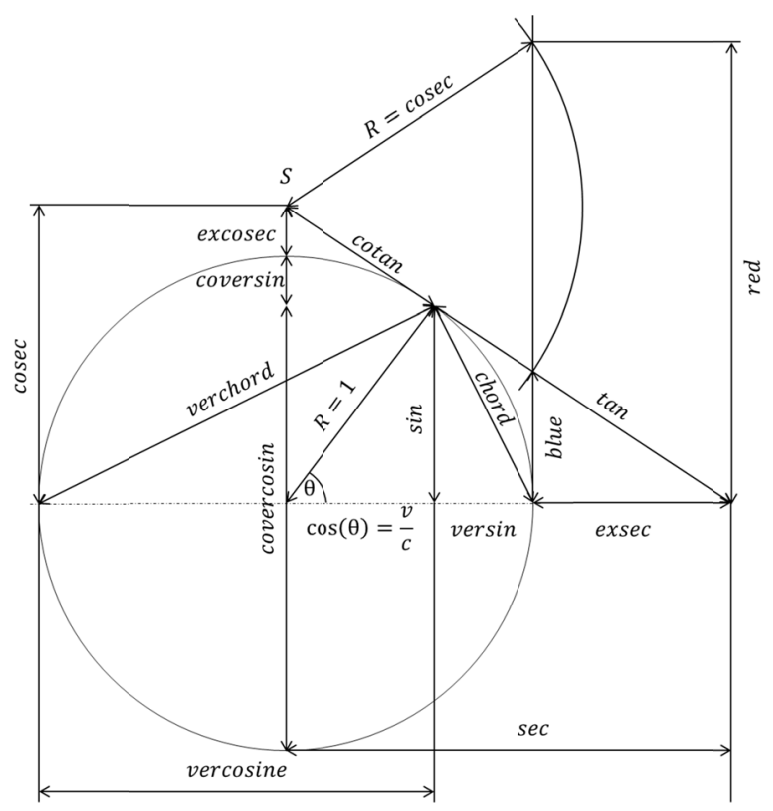

Figure 1. The known trigonometric functions in the circle with radius $R=1$ and the defined value $\cos (\theta)=v / c$

$$
(\mathrm{v} / \mathrm{c} \leq 1)
$$

We can use with advantage the known properties of trigonometric functions and to graphically visualize the relativistic formulae. When we define the $\cos (\theta)=\mathrm{v} / \mathrm{c}(\mathrm{v} / \mathrm{c} \leq 1)$, then we will get automatically the very well known relativistic formulae. With the help of the analytic geometry we can discover some new trigonometric functions outside of the unit circle in order to get other relativistic formulae: Doppler blue $(\theta)$, Doppler red $(\theta)$ and some other new trigonometric functions can be found outside of the unit circle as well.

In Table 2 we have derived values for those trigonometric functions in the circle with radius $\mathrm{R}=1$ based on the $\cos (\theta)=\mathrm{v} / \mathrm{c}(\mathrm{v} / \mathrm{c} \leq 1)$.

Table 2. Relativistic expressions in the circle with radius $\mathrm{R}=1$ and $\cos (\theta)=\mathrm{v} / \mathrm{c}$

\begin{tabular}{lc}
\hline Name & Value \\
\hline cosine & $\cos (\theta)=\frac{v}{c}$ \\
sine & $\sin (\theta)=\sqrt{1-\cos ^{2}(\theta)}=\sqrt{1-\frac{v^{2}}{c^{2}}}$ \\
tangent & $\tan (\theta)=\frac{\sin (\theta)}{\cos (\theta)}=\frac{\sqrt{1-\frac{v^{2}}{c^{2}}}}{\frac{v^{2}}{c}}$ \\
cotangent & $\operatorname{cotan}(\theta)=\frac{\cos (\theta)}{\sin (\theta)}=\frac{\frac{v}{c}}{\sqrt{1-\frac{v^{2}}{c^{2}}}}$ \\
secant & $\sec (\theta)=\frac{c^{2}}{\cos (\theta)}$
\end{tabular}




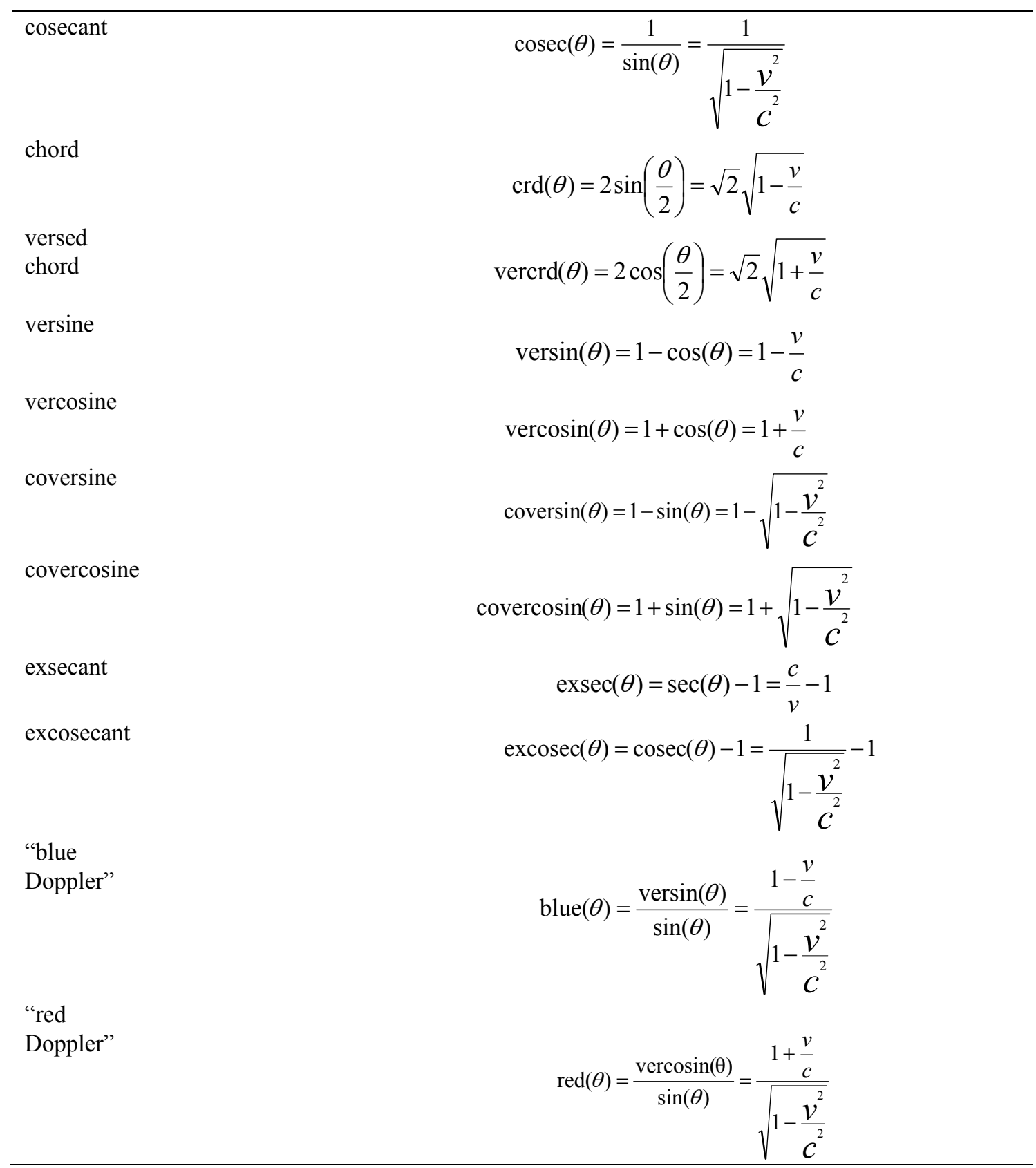

Figure 2 depicts graphically these trigonometric functions with relativistic formulae. The lengths of lines depicted in that Figure 2 were checked by mathematical instruments of René Descartes. We followed the advice of René Descartes: "Many problems can be solved geometrically if we can graphically depict the lengths of those relations". 


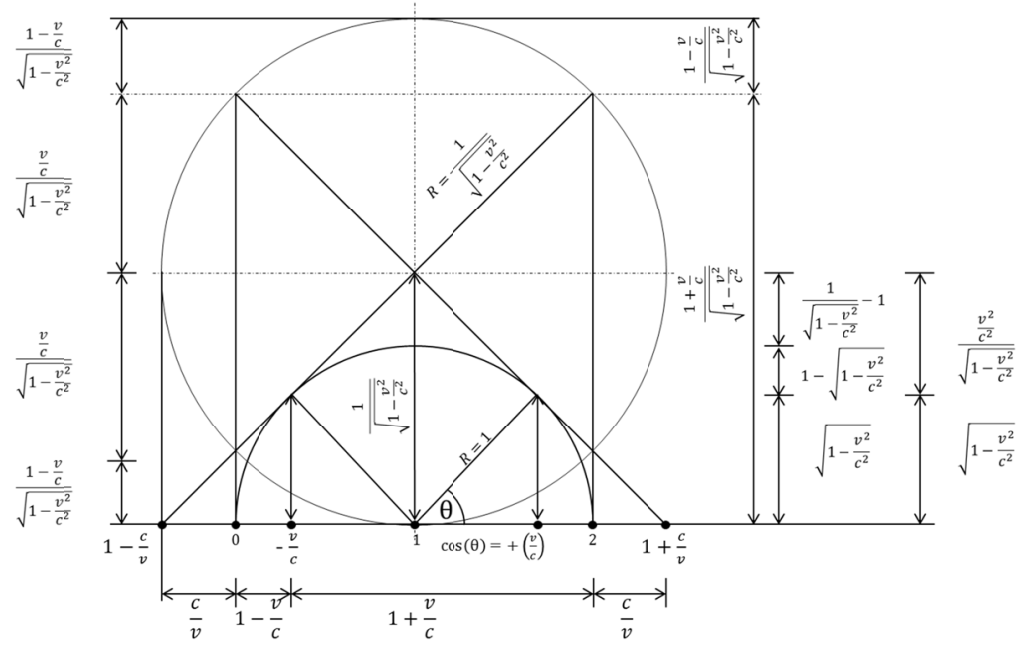

Figure 2. Relativistic formulae in the circle with radius $\mathrm{R}=1$ and the defined value $\cos (\theta)=\mathrm{v} / \mathrm{c}(\mathrm{v} / \mathrm{c} \leq 1)$

The next Figure 3 shows the energy formulae for bosons and fermions. The energy formula for bosons $|\mathrm{E}|=$ $\mathrm{m}_{0}|\mathrm{c}|^{2}$ can be decomposed into two components. The energy formula for fermions $|\mathrm{E}|=\mathrm{m}|\mathrm{c}|^{2}$ can be decomposed into three components.

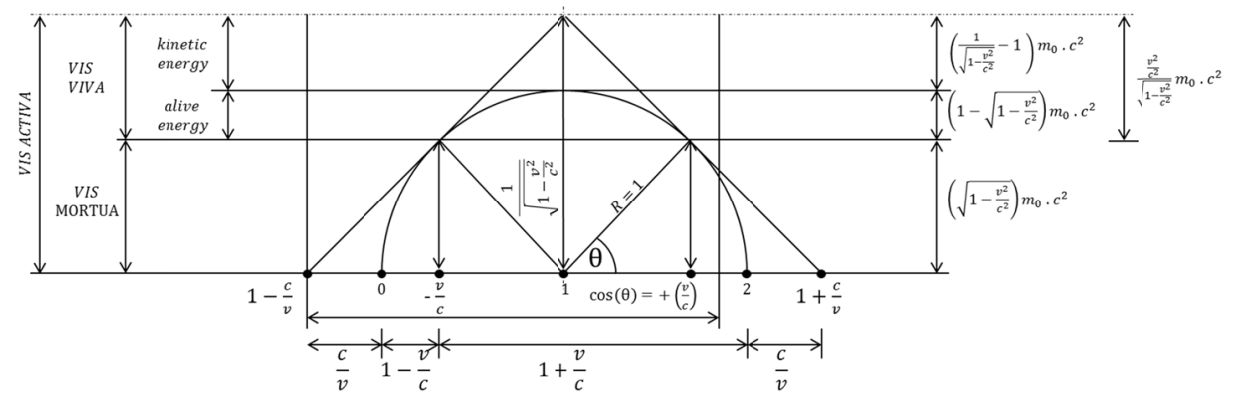

Figure 3. Relativistic formulae for bosons and fermions

Bosons do not react in the free space with other bosons and therefore their energy formula is composed from two contributions only. On the other side fermions eagerly absorb photons from the surroundings and therefore their energy formula can be decomposed into three contributions.

\section{6. $|\mathbf{E}|=\mathbf{m}_{0}|\mathbf{c}|^{2}$ for Photons and $|\mathbf{E}|=\mathbf{m}|\mathbf{c}|^{2}$ for Fermions}

The energy of photons is divided into two parts: "alive energy" and "dead energy" which depend on the longitudinal speed $\mathrm{v}$ of photons in the surroundings (vacuum, air, water, etc.) and can be tested in the photoelectric experiments. Bosons do not react in the free space with other bosons and therefore keep the mass $\mathrm{m}_{0}$ :

$$
|E|=h v=m_{0}|c|^{2}=m_{0}\left(1-\sqrt{1-\frac{v^{2}}{c^{2}}}\right)|c|^{2}+m_{0} \sqrt{1-\frac{v^{2}}{c^{2}}}|c|^{2}
$$

This expression can be interpreted in the Leibniz's terminology from the Specimen dynamicum as:

$$
\text { Vis activa }=\text { Vis viva }+ \text { Vis mortua }
$$

The energy of fermions is composed from three parts: kinetic energy, "alive energy" and "dead energy": 


$$
|E|=\frac{m_{0}}{\sqrt{1-\frac{v^{2}}{c^{2}}}}|c|^{2}=\left(\frac{m_{0}}{\sqrt{1-\frac{v^{2}}{c^{2}}}}-m_{0}\right)|c|^{2}+\left(m_{0}-m_{0} \sqrt{1-\frac{v^{2}}{c^{2}}}\right)|c|^{2}+\left(m_{0} \sqrt{1-\frac{v^{2}}{c^{2}}}\right)|c|^{2}
$$

The kinetic energy and "alive energy" can be fused into one term "vis viva" and we will get the Leibniz's formula for "vis viva" and "vis mortua" for fermions:

$$
|E|=\frac{m_{0}}{\sqrt{1-\frac{v^{2}}{c^{2}}}}|c|^{2}=\frac{\frac{v^{2}}{c^{2}}}{\sqrt{1-\frac{v^{2}}{c^{2}}}} m_{0}|c|^{2}+m_{0}|c|^{2} \sqrt{1-\frac{v^{2}}{c^{2}}}
$$

When the external forces increase the speed of the fermion particle then the external photon mass will be deposited and is visible as a part of the "vis viva" while a part of the internal mass of the gross body transforms from the "dead mass" to the "alive mass":

$$
\frac{m_{0}}{\sqrt{1-\frac{v^{2}}{c^{2}}}}=\left(\frac{1}{\sqrt{1-\frac{v^{2}}{c^{2}}}}-1\right) m_{0}+\left(1-\sqrt{1-\frac{v^{2}}{c^{2}}}\right) m_{0}+\left(m_{0} \sqrt{1-\frac{v^{2}}{c^{2}}}\right)
$$

The total mass of the moving fermion particle $\mathrm{m}$ is composed from three components: 1) the deposited photon mass, 2) the "alive mass", and 3) the "dead mass". The deposited photon mass on the moving fermion can create some new particles in instruments such as the LHC apparatus.

In the period 1881-1905 several researchers derived their formulae for the longitudinal mass and transverse mass. E.g., Thomson in 1881, Searle in 1897 , Poincaré in 1900, Abraham in 1903, Kaufmann in1902, Lorentz in 1904, Einstein in 1905. In March 1906 Max Planck derived the expression for the "vis activa" but he was working with that expression as with "vis viva" (die lebendige Kraft). The evolution of the interpretation of the equation $\mathrm{E}=$ $\mathrm{mc}^{2}$ was many times surveyed, e.g. Leong and Chin in 2005.

The concept of the longitudinal mass and the transverse mass was discussed till the year 1912. Tolman in 1912 introduced the concept of relativistic mass and the concept of the longitudinal mass and transverse mass was not used later in the relativity theories.

There are many discussions on the topics of the "rest mass" and the "relativistic mass", e.g. Okun in 1989, Hecht in 2009 .

See also many contributions on the "vis viva" controversy, e.g. Newton in 1687, Leibniz in 1695, Mach in his "Die Mechanik in Ihrer Entwicklung" in 1900, Hankins in 1965, Iltis in 1971, Smith in 2006.

Table 3 summarizes the series expansions for relativistic formulae that can be used for lower speed aproximations of the relativistic formulae. The aproximations for lower speeds were derived by Descartes, Huygens, Newton, Leibniz, Doppler, etc. The relativistic formulae for the case of the elastic spacetime were derived by Albert Einstein. 
Table 3. Series expansions for used relativistic formulae

\begin{tabular}{ll}
\hline$\frac{1}{\sqrt{1-\frac{v^{2}}{c^{2}}}}$ & $=1+\frac{v^{2}}{2 c^{2}}+\frac{3 v^{4}}{8 c^{4}}+\frac{5 v^{6}}{16 c^{6}}+\frac{35 v^{8}}{128 c^{8}}+O\left(v^{9}\right)$ \\
$\frac{1}{\sqrt{1-\frac{v^{2}}{c^{2}}}}-1$ & $=\frac{v^{2}}{2 c^{2}}+\frac{3 v^{4}}{8 c^{4}}+\frac{5 v^{6}}{16 c^{6}}+\frac{35 v^{8}}{128 c^{8}}+O\left(v^{9}\right)$ \\
$1-\sqrt{1-\frac{v^{2}}{c^{2}}}$ & $=\frac{v^{2}}{2 c^{2}}+\frac{v^{4}}{8 c^{4}}+\frac{v^{6}}{16 c^{6}}+\frac{5 v^{8}}{128 c^{8}}+O\left(v^{9}\right)$ \\
$\sqrt{1-\frac{v^{2}}{c^{2}}}$ & $=1-\frac{v^{2}}{2 c^{2}}-\frac{v^{4}}{8 c^{4}}-\frac{v^{6}}{16 c^{6}}-\frac{5 v^{8}}{128 c^{8}}+O\left(v^{9}\right)$ \\
$\frac{\frac{v^{2}}{c^{2}}}{\sqrt{1-\frac{v^{2}}{c^{2}}}}$ & $=\frac{v^{2}}{c^{2}}+\frac{v^{4}}{2 c^{4}}+\frac{3 v^{6}}{8 c^{6}}+\frac{5 v^{8}}{16 c^{8}}+O\left(v^{9}\right)$ \\
$\frac{1+\frac{v}{c}}{\sqrt{1-\frac{v^{2}}{c^{2}}}}$ & $=1+\frac{v}{c}+\frac{v^{2}}{2 c^{2}}+\frac{v^{3}}{2 c^{3}}+\frac{3 v^{4}}{8 c^{4}}+\frac{3 v^{5}}{8 c^{5}}+O\left(v^{6}\right)$ \\
$\frac{1-\frac{v}{c}}{\sqrt{1-\frac{v^{2}}{c^{2}}}}$ & $=1-\frac{v}{c}+\frac{v^{2}}{2 c^{2}}-\frac{v^{3}}{2 c^{3}}+\frac{3 v^{4}}{8 c^{4}}-\frac{3 v^{5}}{8 c^{5}}+O\left(v^{6}\right)$ \\
\hline &
\end{tabular}

\section{Leibniz and Maupertuis-Two Interpretations of the Quantum of Action}

In 1744 Pierre Louis Maupertuis suggested that the quantity to be minimized was the product of the duration of movement within a system and the "vis viva". This leads to the Planck quantum of action h for photons:

$$
h=m_{0} \lambda_{0} c
$$

where $\mathrm{m}_{0}$ is the photon mass, $\lambda_{0}$ is the photon wavelength and $\mathrm{c}$ is the longitudinal light speed.

In 1689 Gottfried Wilhelm Leibniz proposed that the quantity to be minimized was the product of time and the "vis activa" (See Antognazza, p. 304). This leads to the Leibniz-Planck quantum of formal action $|\mathrm{h}|$ for photons:

$$
|h|=m_{0} \lambda_{0}|c|
$$

where $\mathrm{m}_{0}$ is the photon mass, $\lambda_{0}$ is the photon wavelength and $|\mathrm{c}|$ is the modulus of the light speed.

Both interpretations of the quantum of action have the same numerical value [ $6.62606957(29) \times 10^{-34} \mathrm{~J} \mathrm{~s}$, however the physical meaning of those concepts is different. 
Table 4. Properties of photons described by the modulus of the Matzka-Voigt complex number and the Leibniz-Planck quantum of formal action

Modulus of the Matzka-Voigt complex number $|\mathrm{c}|$
$|c|=\lambda_{0} \nu_{0}=\lambda_{1} \nu_{1}$
Leibniz-Planck quantum of formal action $|\mathrm{h}|$
$|h|=m_{0} \lambda_{0}|c|=m_{1} \lambda_{1}|c|$
Quantum of formal effect $|\mathrm{h}| /|\mathrm{c}|$
$\frac{|h|}{|c|}=m_{0} \lambda_{0}=m_{1} \lambda_{1}$
Quantum of formal consequence $|\mathrm{h}| /|\mathrm{c}|^{2}$
$\frac{|h|}{|c|^{2}}=\frac{m_{0}}{v_{0}}=\frac{m_{1}}{V_{1}}$
Quantum of transmission of information $|\mathrm{h}||\mathrm{c}|$
$|h||c|=m_{0} \lambda_{0}|c|^{2}=m_{1} \lambda_{1}|c|^{2}$

In Table 4 the photon mass $\mathrm{m}_{0}$, wavelength $\lambda_{0}$ and frequency $v_{0}$ describe the photon properties at the source while $\mathrm{m}_{1}, \lambda_{1}, v_{1}$ describe those properties at the receiver, $|\mathrm{c}|$ is the modulus of the light speed, $|\mathrm{h}|$ is the Leibniz-Planck quantum of formal action. These photons transmit to the observer information about the relative velocity, distance, etc. We should find experimentally not only the dependence of the wavelength of the observed photon on the relative motion of the source and the observer but also the dependence of the photon mass on the relative motion of the source and the observer.

Table 5. Two versions of the interpretation of photon properties: Version A and Version B

\begin{tabular}{|c|c|c|}
\hline Parameter of the photon & Version A & Version B \\
\hline $\begin{array}{l}\text { Longitudinal photon speed in the } \\
\text { medium }\end{array}$ & $\rightarrow(\mathrm{v})$ & $\begin{array}{l}\text { c (light speed) corrected for that } \\
\text { medium }\end{array}$ \\
\hline $\begin{array}{c}\text { Transverse vibrational } \\
\text { photon speed }\end{array}$ & $\downarrow\left(c \sqrt{1-\frac{v^{2}}{c^{2}}}\right)$ & $\mathrm{c}$ (light speed) \\
\hline Modulus of the light speed & $|\mathrm{c}|$ & not defined \\
\hline "Vis activa" of photon & $|\mathrm{h}| \mathrm{v}=\mathrm{m}_{0}|\mathrm{c}|^{2}$ & $\mathrm{~h} v=\mathrm{m}_{0} \mathrm{c}^{2}$ \\
\hline "Vis viva" of photon & & $\mathrm{m}_{0} \mathrm{c}^{2}$ \\
\hline "Vis mortua" of photon & & not defined \\
\hline Rest mass of photon & $\mathrm{m}_{0}$ & 0 \\
\hline Elasticity of & $\begin{array}{c}\text { transverse vibrational } \\
\text { particle speed }\end{array}$ & space-time \\
\hline
\end{tabular}

Table 5 brings information that the photon mass of the given photon is both $\mathrm{m}_{0}$ at the maximum speed $\mathrm{c}$ or at the speed $\mathrm{v}=0$. We can manipulate with the longitudinal speed $\mathrm{v}$ in different media and thus modify the ratio of the 
"vis viva" and "vis mortua" of that photon. The quantity of "vis viva" of that photon can be experimentally tested in photoelectric experiments.

\section{Photoelectric Effect-The Test of This Concept}

Philipp Lenard in 1902 and R.A. Millikan in 1916 experimentally and Albert Einstein in 1905 theoretically described the photoelectric effect as:

$$
K_{\max }=h v-W
$$

where $\mathrm{K}_{\max }$ is the maximum kinetic energy of an ejected electron, $\mathrm{h}$ is the Planck constant and $v$ the frequency of the incident photon, the term $\mathrm{W}$ is the work function which describes the minimum energy in order to remove a delocalized electron from the surface of the metal.

We propose to test this formula:

$$
\left(\frac{1}{\sqrt{1-\frac{v_{e}^{2}}{c^{2}}}}-1\right) m_{e}|c|^{2}=h v-\left(m_{p h} \sqrt{1-\frac{v_{p h}^{2}}{c^{2}}}\right)|c|^{2}=m_{p h}\left(1-\sqrt{1-\frac{v_{p h}^{2}}{c^{2}}}\right)|c|^{2}
$$

where $m_{e}$ is mass of the electron, $v_{e}$ its speed after the ejection, $m_{p h}$ is the mass of the photon and $v_{p h}$ the photon longitudinal speed in that medium (air, water, metal, etc.), $|\mathrm{c}|$ is the modulus of the light speed, $\mathrm{h}$ is the Planck constant and $v$ the frequency of the incident photon. In this concept "vis viva" of photon determines the kinetic energy of the ejected electron. By the modification of the photon longitudinal speed $\mathrm{v}_{\mathrm{ph}}$ we can manipulate with the kinetic energy of the ejected electron.

\section{9. "Vis viva" of Fermions-The Test of This Concept}

We propose to repeat Poleni's experiment (1721) and 's Gravesande's experiment (1729) where we expect the dependence on the "vis viva" of the moving body and not on the kinetic energy of the moving body:

$$
|E|=\frac{\frac{v^{2}}{c^{2}}}{\sqrt{1-\frac{v^{2}}{c^{2}}}} m_{0}|c|^{2}
$$

where $\mathrm{v}$ is the speed of the moving fermion with the rest mass $\mathrm{m}_{0}$. There is a well documented long discussion ("vis viva" controversy) on the difference of the energy acting in time and the energy acting in space: $\mathrm{PhD}$ Thesis from Carolyn Merchant Iltis: "The Controversy over Living Force: From Leibniz to D'Alembert" written in 1967.

\section{0. "Quantity of Motion"-Momentum of Fermions-The Test of This Concept}

Suppose there are two fermion particles of equal mass $\mathrm{m}_{0}$, one is stationary (particle 2) and one is approaching (particle 1) the particle 2 at a speed v. Their center of mass is moving at speed v/2. During the collision the photon mass adsorbed on the moving particle 1 will be transported and deposited on the stationary particle 2 . The "quantity of motion"- momentum of this system M can be described as:

$$
M=m v=\left[\frac{1}{\sqrt{1-\frac{v^{2}}{c^{2}}}} m_{0}+\frac{1}{\sqrt{1-\frac{v^{2}}{c^{2}}}} m_{0}\right] \frac{v}{2}=\frac{m_{0} v}{\sqrt{1-\frac{v^{2}}{c^{2}}}}
$$

Because of the symmetry, after the collision both particles must be moving from the center of mass at partner speed. The particle 1 is now stopped and the particle 2 is moving at speed $\mathrm{v}$. The particles exchanged their speed and the photon mass $\mathrm{m}_{\text {photon }}$ brought into the system by the moving particle 1 :

$$
m_{\text {photon }}=\left(\frac{1}{\sqrt{1-\frac{v^{2}}{c^{2}}}}-1\right) m_{0}
$$


We should focus our attention on the photon mass transfer $m_{\text {photon }}$ from the moving particle 1 onto the stationary particle 2 to determine experimentally this quantity. This approach leads us to the old concept introduced into the science by Antoine Lavoisier.

\section{Caloric as the Substance of Heat}

There is one version of the caloric theory that was introduced into the science by Antoine Lavoisier in 1783 who proposed a "subtle fluid" called caloric as the substance of heat causing the vibration of individual particles. Since that time there is a permanent discussion if heat can be explained by the caloric absorption causing the vibration of particles or by the vibration of individual particles without any exchange of (fictious) caloric with the surroundings.

It is valuable to re-read contributions of researchers who were revisiting and developing the caloric concept during the $20^{\text {th }}$ and begin of the $21^{\text {th }}$ centuries: e.g., Callendar in 1910, Brown in 1949 and in 1950, Kuhn in 1958, Fox in 1971, Morris in 1972, Psillos in 1994, Chang in 2003, Mareš et al. in 2008.

The gist of this contribution is to identify the caloric exchange with the photon mass echange from the surroundings. The quantitative predictions of this concept can be verified using the instrumental technique available at the beginning of the $21^{\text {st }}$ century.

\section{Conclusions}

The Matzka-Voigt complex number $\mathrm{z}_{\mathrm{MV}}$ with its modulus $|\mathrm{c}|=299,792,458 \mathrm{~ms}^{-1}$ was postulated as the decomposition algorithm for the quantity "c- the light speed constant". Trigonometric functions were used to graphically visualize the relativistic formulae and to decompose the relativistic formulae into their components. The expression $|\mathrm{E}|=\mathrm{m}_{0}|\mathrm{c}|^{2}$ describes the "vis activa" of photons, one its part "vis viva" of photons can be tested in the photoelectric experiments. The expression $|\mathrm{E}|=\mathrm{m}|\mathrm{c}|^{2}$ describes the "vis activa" of fermion particles, one its part "vis viva" of fermions can be tested in the Poleni's and 'sGravesande's experiment, one its part the kinetic energy can be tested in the photoelectric experiments. The difference between the Planck quantum of action $\mathrm{h}=\mathrm{m} \lambda \mathrm{c}$ based on the "vis viva" of photons and the Leibniz-Planck quantum of formal action $|\mathrm{h}|=\mathrm{m} \lambda|\mathrm{c}|$ based on the "vis activa" of photons was stated. Two versions of the interpretation of the photon properties were compared. Three experiments were proposed for testing of this concept.

\section{Acknowledgements}

This work was supported by the GMS Agency (Contract Number 69110/1992). We have found the valuable support on the web site www.wolframalpha.com with the corrections of used formulae. The Wikipedia encyclopedia was frequently used to survey topics discussed in this contribution.

\section{References}

Abraham, M. (1903). Prinzipien der Dynamik des Elektrons. Ann. Phys., 315, 105-179. http://dx.doi.org/10.1002/andp.19023150105

Antagnozza, M. R. (2011). Leibniz. An Intellectual Biography (p. 304). Cambridge: Cambridge University Press.

Argand, J. R. (1806). Essai sur une manière de represésenter des quantités imaginaires dans les constructions géometriques. Retrieved from http://archive.org/details/essaisurunemani00argauoft; ark:/13960/t69314066

Barett, J. F. (2011). The hyperbolic theory of special relativity. Retrieved from http://arxiv.org/ftp/arxiv/papers/1102/1102.0462.pdf

Bros, J. (2005). The Geometry of Relativistic Spacetime: from Euclid's Geometry to Minkowski's Spacetime. Séminaire Poincaré, 1, 1-45. Retrieved from http://www.bourbaphy.fr/bros.pdf

Brown, S. C. (1949). Count Rumford and the Caloric Theory of Heat. Proceedings of the American Philosophical Society, 93, 316-325. http://dx.doi.org/10.2307/3143157

Brown, S. C. (1950). The Caloric Theory of Heat. Am. J. Phys., 18, 367-373. http://dx.doi.org/10.1119/1.1932596

Callendar, H. L. (1910). The Caloric Theory of Heat and Carnot's Principle. Proc. Phys. Soc. London, 23, 153. http://dx.doi.org/10.1088/1478-7814/23/1/315

Carroll, S. M. (2004). Spacetime and geometry. An introduction to general relativity. San Francisco: Addison Wesley.

Cauchy, A. L. (1821). Cours d'analyse de l'École royale polytechnique. Retrieved from http://books.google.cz/books/about/Cours_d_analyse_de_1_\%C3\%89cole_royale_polyt.html?id=n60AAAA 
AMAAJ\&redir_esc $=\mathrm{y}$

Chang, H. S. (2003). Preservative realism and its discontents: Revisiting caloric. Philosophy of Science, 70, 902-912. http://dx.doi.org/10.1086/377376

Chocholová, M. (2008). Wilhelm Matzka and the Historical Development of Complex Numbers. WDS'08 Proceedings of Contributed Papers, Part I, 38-42. Retrieved from http://citeseerx.ist.psu.edu/viewdoc/download?doi=10.1.1.186.7663\&rep=rep1\&type=pdf

Chocholová, M., \& Štoll, I. (2011). Wilhelm Matzka (1798-1891). Prague: Matfyzpress.

Crabbe, A. (2004). Alternative conventions and geometry for Special Relativity. Annales de la Foundation Louis de Broglie, 29, 589-608. Retrieved from http://aflb.ensmp.fr/AFLB-294/aflb294m097.pdf

Delphenich, D. H. (2005). Projective Geometry and Special Relativity. Retrieved from http://arxiv.org/ftp/gr-qc/papers/0512/0512125.pdf

Descartes, R. (1637). La Géométrie.

Doppler, C. (1842). Über das farbige Licht der Doppelsterne und einiger anderer Gestirne des Himmels. Abhandlungen der Königlichen Böhmischen Gesellschaft der Wissenschaften. V. Folge, Bd.2, 465-482.

Dragon, N. (2012). Geometry of Special Relativity. Retrieved from http://www.itp.uni-hannover.de/ dragon/rel_e.pdf

Dray, T. (2003). The Geometry of Special Relativity. Retrieved from http://hs.loswego.k12.or.us/z-pricem/AP\%20Physics/11\%20Relativity/01\%20Special\%20Relativity/geome try.pdf

Einstein, A. (1905). Ueber einer die Erzeugung und Verwandlung des Lichtes betreffenden heuristischen Gesichtspunkt. Annalen der Physik, 17(6) 132-148. http://dx.doi.org/10.1002/andp.19053220607

Einstein, A. (1905). Zur Elektrodynamik bewegter Körper. Ann. Phys., 17, 891-921. http://dx.doi.org/10.1002/andp.19053221004

Einstein, A. (1906). Über eine Methode zur Bestimmung des Verhältnisses der transversalen und longitudinalen Masse des Electrons. Ann. Phys., 21, 583-586.

Ernst, A., \& Hsu, J. P. (2001). First Proposal of the Universal Speed of Light by Voigt in 1887. Chinese Journal of Physics, 39, 211-230. Retrieved from http://psroc.phys.ntu.edu.tw/cjp/v39/211.pdf

Feynman, R. P., Leighton, R. B., \& Sands, M. (2005). The Feynman Lectures on Physics (Definitive ed.). San Francisco, California: Pearson Addison-Wesley.

Fox, R. (1971). The Caloric Theory of Gases from Lavoisier to Regnault. Oxford: Clarendon Press.

Gauss, C. F. (1831). Theoria residuorum biquadraticorum. Commentatio secunda.

Hankins, T. L. (1965). Eighteenth-Century Attempts to Resolve the Vis viva Controversy. Isis, 56, 281-297. Retrieved from http://www.jstor.org/stable/228103

Hecht, E. (2009). Einstein on mass and energy, Am. J. Phys., 77, 799-806. http://dx.doi.org/10.1119/1.3160671

Iltis, C. M. (1967). The Controversy over Living Force: Leibniz to D'Alembert. (Doctoral dissertation, Graduate School of the University of Wisconsin).

Iltis, C. M. (1971). Leibniz and the Vis Viva Controversy. Isis, 62, 21-35. Retrieved from http://www.jstor.org/stable/228997

Kaufmann, W. (1902). The Electromagnetic Mass of the Electron. Physikalische Zeitschrift, 4, 54-56. Retrieved from http://wikilivres.ca/wiki/Die_elektromagnetische_Masse_des_Elektrons

Kuhn, T. S. (1958). The Caloric Theory of Adiabatic Compression. Isis, 49, 132-140. http://dx.doi.org/10.2307/226926

Lavoisier, A.-L. de. (1783). Mémoire sur la chaleur. Paris: Académie royale des sciences.

Leibniz, G. W. (1689-1690). Dynamica de Potentia et Legibus Naturae Corporeae.

Leibniz, G. W. (1695). Specimen dynamicum. Philosophical Papers and Letters, Reidel, Dordrecht.

Lenard, P. (1902). Ueber die lichtelektrische Wirkung. Annalen der Physik, 313(5), 149-198. http://dx.doi.org/10.1002/andp.19023130510 
Leong, W. C., \& Chin, Y. K. (2005). Conceptual Development of Einstein's Mass-energy Relationship. New Horizons in Education, 51, 56-66.

Lorentz, H. A. (1904). Electromagnetic phenomena in a system moving with any velocity smaller than that of light. Proceedings of the Royal Netherlands Academy of Arts and Sciences, 6, 809-831. Retrieved from http://en.wikisource.org/wiki/Electromagnetic_phenomena

Mach, E. (1933). Die Mechanik in Ihrer Entwicklung. Reprographischer Nachdruck 1991 der 9. Auflage, Leipzig 1933. Retrieved from http://echo.mpiwg-berlin.mpg.de/content/pre-physics/physics/mach_mechanik_1883

Mareš, J. J., Hubík, P., Šesták, J., Špička, V., Krištofik, J., \& Stávek, J. (2008). Phenomenological approach to the caloric theory of heat. Thermochimica Acta, 474(1-2), 16-24. http://dx.doi.org/10.1016/j.tca.2008.05.001

Matzka, W. (1850). Versuch einer richtigen Lehre von der Realität der vorgeblich imaginären Grössen der Algebra, oder einer Grundlehre von der Ablenkung algebraischer Grössenbeziehungen. Prague: J. G. Calve.

Maupertuis, P. L. M. (1744). Accord de différentes lois de la nature qui avaient jusqu'ici paru incompatibles, Mém. Ac., $\quad$ Berlin, $\quad$ p. $267 . \quad$ Retrieved from http://fr.wikisource.org/wiki/Accord_de_diff\%C3\%A9rentes_loix_de_la_nature_qui_avoient_jusqu $\% \mathrm{E} 2 \% 8$ 0\%99ici_paru_incompatibles

Maxwell, J. C. (1865). A Dynamical Theory of the Electromagnetic Field, Phil. Trans. Royal Soc., 155, 459-512. http://dx.doi.org/10.1098/rstl.1865.0008

Millikan, R. A. (1916). A Direct Photoelectric Determination of Planck's "h". Physical Review, 7(3), 355-388. http://dx.doi.org/10.1103/Phys.Rev.7.355

Morris, R. J. (1972). Lavoisier and the Caloric Theory. British Society for the History of Science, 6, 1-38. http://dx.doi.org/10.1017/S000708740001195X

Naber, G. L. (2012). The Geometry of Minkowski Spacetime. An Introduction to the Mathematics of the Special Theory of Relativity. New York: Springer.

Newton, I. (1687). Philosophiae Naturalis Principia Mathematica. Retrieved from http://www.newtonproject.sussex.ac.uk/catalogue/record/NATP00072

Newton, I. (1717). Optics, or a Treatise of the Reflections, Refractions, Inflections and Colours of Light (2nd ed.). Retrieved http://s253639974.onlinehome.fr/branestorming2/wp-content/uploads/2012/09/Opticks_Newton.pdf

Okun, B. L. (1989). The Concept of Mass. Physics Today, 42, 31-36. http://dx.doi.org/10.1063/1.881171

Planck, M. (1901). On the Energy Distribution in the Blackbody Spectrum. Ann. Phys., 4, 553-563.

Planck, M. (1906). Das Prinzip der Relativität und die Grundgleichungen der Mechanik, Verhandlungen Deutsche Physikalische Gesellschaft, 8, 136-141. Retrieved from http://wikilivres.ca/wiki/Das_Prinzip_der_Relativit\%C3\%A4t_und_die_Grundgleichungen_der_Mechanik

Poincaré, H. (1900). La Théorie de Lorentz et le principe de reaction, Archives néderlandaises des sciences $\begin{array}{lllll}\text { exactes et } & \text { naturelles, } & \text { 252-278. } & \text { Retrieved } & \text { from }\end{array}$ http://www.youscribe.com/catalogue/livres/savoirs/sciences-formelles/la-theorie-de-lorentz-et-le-principe-d e-reaction- 248275

Poleni, J. M. (1721). Sur la force des corps en movement. Paris, Mem. Acad. Sci., 81-85.

Psillos, S. (1994). A philosophical study of the transition from the caloric theory of heat to thermodynamics: resisting the pessimistic meta-induction. Stud. Hist. Phil. Sci., 25, 159-190. http://dx.doi.org/10.1016/0039-3681(94)90026-4

Rindler, W. (1991). Introduction to special relativity (2nd ed.). Oxford University Press.

Robb, A. A. (1911). Optical geometry of motion: A new view of the theory of relativity. Cambridge: W. Heffer.

Searle, G. F. C. (1897). On the steady motion of an electrified ellipsoid, Philosophical Magazine, 44, 329-341. http://dx.doi.org/10.1080/14786449708621072

`s Gravesande, W. J. (1729). Remarques sur la force des corps en movement et sur le choc. Journal littéraire de la Haye, 13, Pt.I, 189-197, Pt. II, 407-432. 
Smith, G. E. (2006). The vis viva dispute: A controversy at the dawn of dynamics. Physics Today (October), 31-36.

Retrieved

from http://philoscience.unibe.ch/documents/MaterialFS11/PS-Leibniz11/SmithG2006Vis.pdf

Taylor, E., \& Wheeler, J. A. (1992). Spacetime physics (2nd ed.). W. H. Freeman \& Co.

Thomson, J. J. (1881). On the electric and magnetic effects produced by the motion of electrified bodies. Philosophical Magazine, 11, 229-249. http://dx.doi.org/10.1080/14786448108627008

Tipler, P., \& Llewellyn, R. (2002). Modern physics (4th ed.). W. H. Freeman \& Co.

Tolman, R. C. (1912). Non-Newtonian Mechanics. The mass of a Moving Body. Philosophical Magazine, 23, 375-380. http://dx.doi.org/10.1080/14786440308637231

Ungar, A. A. (2009). Einstein's special relativity: The hyperbolic geometric viewpoint. Retrieved from http://www.phil-inst.hu/ $\sim$ szekely/pirt_bp_2/papers/ungar_09_ft.pdf

Varićak, V. (1911). Anwendung der Lobatschefkijschen Geometrie in der Relativtheorie. Phys. Zeit., 11, 93-96.

Voigt, W. (1887). Über das Doppler'sche Prinzip. Göttinger Nachrichten, 1887(2), 41-51. http://en.wikisource.org/wiki/Translation:On_the_Principle_of_Doppler

Wessel, C. (1799). Om Directionens analytiske Betegning, et Forsøg anvendt fornemmeling til plane og sphaeriske Polygoners Opløsning. (On the analytical representation of direction: an attempt applied chiefly to solving plane and spherical polygons)

Whittaker, E. T. (1910). A history of the theories of aether and electricity. Dublin: Longman Green Co.

\section{Copyrights}

Copyright for this article is retained by the author(s), with first publication rights granted to the journal.

This is an open-access article distributed under the terms and conditions of the Creative Commons Attribution license (http://creativecommons.org/licenses/by/3.0/). 